\title{
La práctica forense en la utilización de los motivos de revisión y sus revelaciones ${ }^{1}$
}

\author{
Michelle Matilde Rizo Pereira \\ Labora en el Poder Judicial
}

\begin{abstract}
Resumen
En esta investigación se analizan los fallos de la Sala de lo Penal de la Corte Suprema de Justicia a la luz de la práctica forense en la utilización de los motivos de la acción de revisión. Este estudio refleja los aciertos y desaciertos de la técnica jurídica utilizada por los litigantes en el cumplimiento de las exigencias, presupuestos y limitaciones que exige La acción de revisión. Es por ello, que surge la necesidad de incentivar el estudio de manera integral en los estudiantes de la carrera de derecho, abogados litigantes y operadores del sistema de justicia penal.

El presente texto procura reforzar lo establecido en el Código Procesal Penal, de los Procedimientos Especiales, contenidos en el Titulo IV, Capítulo III, de la revisión de sentencia. No pretende renovar instituciones o pensamientos, sino aportar reflexiones a la práctica forense para mejorar, cumplir y satisfacer la finalidad de la acción de revisión como es favorecer o mejorar la condición del sujeto injustamente condenado, que por su naturaleza y características de la institución, las Salas Penales competentes no pueden oficiosamente accionar a favor del condenado, sin perjuicio de conocer y resolver sobre aspectos constitucionales o violación de derechos y garantías del condenado.
\end{abstract}

Palabras clave: revisión / sentencia firme / condenado / tribunales

\begin{abstract}
This research analyzes the rulings of the Criminal Court of the Supreme Court of Justice with the aid of forensic practice in the use of the grounds for a judicial review process. This study shows the successes and of the judicial techniques used by the litigants in the observance of the procedures, the budgets and the limitations imposed by the judicial review process. Therefore, among law students, trial lawyers and operators of the criminal justice system comes the need to encourage the study comprehensively.

This text attempts to strengthen the provisions in the Code of Criminal Procedure, Special Procedures contained in Title IV, Chapter III, of the revision of the sentence.

1 El presente artículo es el resultado del trabajo de investigación realizado para obtener el título de Máster en Derecho Penal y Derecho Procesal Penal; el cual además de ser evaluado por un Tribunal integrado por tres académicos; posteriormente, fue arbitrado por una Comisión a efectos de seleccionar a los participantes del II Encuentro de Investigación de Postgrado de la Universidad Centroamericana, Agosto 2010.
\end{abstract}


Revista de Derecho

This document does not intend to renew institutions and thoughts, but to provide ideas to improve the condition of the subject wrongly convicted. We understand that the competent Criminal Courts, by the nature and characteristics of the institution, cannot operate informally in favor of the convicted person, and they are subject to hear rule on constitutional matters or violation of rights and guarantees of the convicted

Key words: rehearing, retrial, judicial review/ final judgment/ convicted prisoner/ courts

\section{Introducción}

Nicaragua desarrolla un modelo procesal penal moderno ajustado a las directrices consagradas en la Constitución Política, caracterizado por un sistema acusatorio con sentido garantista por la defensa efectiva de derechos y garantías, con juicio oral, público bajo los principios de contradicción e inmediación.

El presente texto procura reforzar lo establecido en el Código Procesal Penal, de los Procedimientos Especiales, contenidos en el Titulo IV, Capítulo III, dela revisión de sentencia. No pretende renovar instituciones o pensamientos, sino aportar reflexiones a la práctica forense para mejorar, cumplir y satisfacer la finalidad de la acción de revisión como es favorecer o mejorar la condición del sujeto injustamente condenado, que por su naturaleza y características de la institución, las Salas Penales competentes no pueden oficiosamente accionar a favor del condenado, sin perjuicio de conocer y resolver sobre aspectos constitucionales o violación de derechos y garantías del condenado.

La Sala Penal de la Corte Suprema de Justicia como Tribunal de revisión declara inadmisible la mayoría de las acciones de revisiones interpuestas, ya que los litigantes demuestran falta de tecnicismo jurídico o desconocimiento de la norma, aún cuando los requisitos de admisibilidad son claros, precisos y concisos, obviando algunos abogados el marco legal establecido para su admisibilidad.

Para el desarrollo del estudio se empleó una metodología, investigativa, documental y analítica, que permitió apreciar los aciertos y desaciertos en torno a la utilización de los motivos de revisión. 


\section{La acción de revisión}

La acción de revisión no es más que un procedimiento extraordinario que tiende a rectificar una sentencia condenatoria firme, con base en el acaecimiento de situaciones jurídicas nuevas.

El recurso de revisión puede definirse como el remedio procesal que dirigido contra las sentencias condenatorias pasadas en autoridad de cosa juzgada, tiende, en un aspecto, a demostrar, mediante la alegación de circunstancias ajenas al proceso fenecido por ser sobrevinientes o desconocidas al tiempo de dictarse la sentencia final, que el hecho no existió o no fue cometido por el condenado o encuadra en una norma más favorable, y en otro aspecto a lograr la aplicación retroactiva de una ley más benigna que la aplicada en el fallo. (Palacios, 1998) (p. 199)

Quedan excluidos todos los pronunciamientos que no son sentencia con decisión sobre el fondo y la sentencia absolutoria. La decisión definitiva sobre el fondo responde a la necesidad de que se trate de una causa agotada formal y sustancialmente. La exclusión de la sentencia absolutoria tiene su fundamento en el ne bis in idem como principio de seguridad jurídica, y en la prohibición de la reformatio impejus en cuanto a garantía de no perjudicar una situación definitivamente adquirida.

La legitimación para impugnar se extiende a personas que no han participado en el proceso; ya que todas las partes del proceso tienen derecho a impugnar las resoluciones que les causen agravios, adoptadas por los órganos judiciales y se dirige contra una sentencia firme sobre un determinado hecho; supone asimismo que solo pueda ser viable cuando se trate de sanar situaciones acreditadamente injustas en las que sea evidente que la posible resulta de la acción de revisión favorezca al condenado, en cuanto a la inocencia respecto al hecho que sirvió de fundamento a la sentencia de condena.

No hay plazo para interponer la acción de revisión y la facultad para hacerlo subsiste aún después de la muerte del condenado. Dado que se trata de una persona que soporta las consecuencias de una condena posiblemente injusta, razón por lo cual, el dar lugar a la revisión implica una pública reivindicación, y en su caso, la consiguiente reparación material, moral y social. 
Revista de Derecho

Son tribunales de revisión la Sala Penal de la Corte Suprema de Justicia cuando se trata de comisión de delitos graves y las Salas Penales de los Tribunales de Apelaciones en los delitos menos graves.

\section{Requisitos objetivos}

La acción de revisión procederá contra las "sentencias firmes"

Artículo 337.- Procedencia. En favor del condenado o de aquel a quien se haya impuesto una medida de seguridad, en los siguientes casos: 1 . Cuando los hechos tenidos como fundamento de la condena resulten inconciliables o excluyentes con los establecidos por otra sentencia penal firme; 2 . Cuando la sentencia condenatoria se haya fundado en prueba falsa o en veredicto ostensiblemente injusto a la vista de las pruebas practicadas; 3 . Si la sentencia condenatoria ha sido pronunciada a consecuencia de prevaricato, cohecho, violencia, maquinación fraudulenta o cualquier otro delito cuya existencia se haya declarado en fallo posterior firme, salvo que se trate de alguno de los casos previstos en el inciso siguiente; 4. Cuando se demuestre que la sentencia es consecuencia directa de una grave infracción a sus deberes cometida por un juez o jurado, aunque sea imposible proceder por una circunstancia sobreviniente; 5. Cuando después de la condena sobrevengan o se descubran nuevos hechos o nuevos elementos de prueba que, solos o unidos a los ya examinados en el proceso, evidencien que el hecho o una circunstancia que agravó la pena no existió, que el condenado no lo cometió o que el hecho cometido no es punible o encuadra en una norma más favorable; 6. Cuando deba aplicarse retroactivamente una ley posterior más favorable, o cuando la ley que sirvió de base a la condenatoria haya sido declarada inconstitucional, o, 7. Cuando se produzca un cambio jurisprudencial que favorezca al condenado, en las decisiones de la Corte Suprema de Justicia o sus Salas. La revisión procederá aun cuando la pena o medida de seguridad haya sido ejecutada o se encuentre extinguida.

Aquellos fallos que adquieran condición de firmeza vienen a constituir uno de los presupuestos indispensables para su debido trámite.

$\mathrm{Al}$ señalar el legislador como sentencia firme debe concebirse que la acción deba ser intentada contra la que fue pronunciada por el tribunal de juicio o juez de derecho. 
Para que proceda la acción de revisión se requiere que la sentencia penal cuestionada se encuentre firme y únicamente se puede promover a favor del condenado; sentencia firme es aquella contra la cual no cabe recurso alguno sea ordinario o extraordinario. El Código Procesal Penal deja establecido el principio de impugnabilidad objetiva, sin embargo la práctica forense denota que dicho presupuesto no es tomado en cuenta por los litigantes.

La acción de revisión únicamente puede interponerse a favor de un reo con sentencia condenatoria firme, siempre y cuando se trate de un punto o hecho nuevo el que va a alegar, para tratar de cambiar o destruir la sentencia que lo condenó. Los accionantes interpusieron dos escritos de acción de revisión en dos fechas diferentes y a favor de dos reos condenados por el mismo delito ... El primer accionante no demostró que estuviese firme la sentencia ... El segundo condenado manifiesta que la sentencia fue recurrida de apelación y confirmada, por lo que su acción debió dirigirse en contra de la sentencia definitiva condenatoria, y no en contra de la sentencia interlocutoria de Auto de Prisión, y no menciona nueva prueba ni hecho nuevo alguno. La acción es extremadamente formalista con causales taxativas establecidas, y los accionantes no hicieron una correcta interposición de la misma, pues sus alegatos son propios de un recurso de apelación y, pretendieron, hacer una nueva valoración de las pruebas rendidas en el proceso... (Sentencia No. 4, 2004).

El Código Procesal Penal debió exigir como requisito además de la sentencia firme, haber agotado los recursos ordinarios y extraordinarios, $y$, una vez firme la sentencia condenatoria considerada injusta, fuese objeto de acción revisoria siempre y cuando surgiera una causal contenida en la acción de revisión.

Una sentencia en delito grave queda firme cuando se han agotado los recursos ordinarios y extraordinarios o, cuando se agotó el recurso ordinario y no se hizo uso del recurso extraordinario. $O$ bien cuando no se agotó el recurso ordinario.

En los delitos menos graves la sentencia adquiere firmeza cuando se agota el recurso ordinario o, bien cuando no se hace uso del recurso ordinario. 
El accionante en ningún momento separa, explica y fundamenta cada uno de los reparos que interpone, por el contrario, realiza una exposición de los hechos como si fuera un recurso de instancia la que tiene como propósito revertir la resolución, sin explicarse las razones de orden jurídico, los defectos que menciona en la integridad y validez de lo resuelto, o cuál fue el agravio sufrido, por lo que impide comprender la inconformidad que presenta y cómo suplir el interés procesal que justifica un nuevo estudio del fallo. De manera genérica e indiscriminada el gestionante acusa una serie de defectos sin concretar en qué consisten éstos, o bien sin indicar cómo inciden los mismos. La queja que se interpone lejos de acreditar los defectos o yerros que en ella se acusan, lo que pretende en realidad es un nuevo y parcial análisis de los diferentes elementos de juicio que fueron discutidos en las instancias anteriores ... (Sentencia No. 60, 2004).

No son susceptibles de revisión las sentencias absolutorias, ya que quedan tácitamente prohibido en cumplimiento a los principios de ne bis in idem y de prohibición de la reformatio in peius.

La accionante, ha demostrado con documento auténtico ser la madre del condenado, con lo que ha satisfecho el requisito subjetivo ... La causa ha sido tramitada al amparo del Código de Instrucción Criminal, y al manifestar en su escrito que la judicial de primera instancia, no ha dictado sentencia, es evidente que no existe sentencia firme, y que la causa aún está sometida al conocimiento del juez de primera instancia, en donde no se ha dictado la sentencia condenatoria, y que ser objeto de recursos ordinarios y extraordinario ... Razón por la cual es prematuro accionar ante la carencia del elemento objetivo antes referido. (Sentencia No. 22, 2004).

\section{Requisitos subjetivos}

El Código Procesal Penal en el artículo 338 establece los "Sujetos legitimados. Podrán promover la revisión: 1. El condenado o aquél a quien se le ha aplicado una medida de seguridad; si es incapaz, sus representantes legales; 2 . El cónyuge, el compañero en unión de hecho estable, los parientes dentro del segundo grado de consanguinidad, si el condenado ha fallecido; 3. El Ministerio Público, y, 4. La Defensoría Pública”. 
El artículo 337 CPP dispone que "La acción de revisión procede contra las sentencias firmes y en favor del condenado" ... mientras que el numeral 338 CPP señala expresamente quiénes son los sujetos legitimados procesalmente para promover la revisión. La ley excluye la posibilidad de que el abogado defensor pueda ejercer este derecho, ya que solo le queda permitido al condenado o aquel a quien se le haya impuesto una medida de seguridad, por supuesto que el procedimiento revisoria permite la designación de un abogado defensor al momento de interponer la acción.

El abogado defensor del reo no está legitimado como sujeto procesal para promover la acción. La inobservancia de los arts. 337, 338, 339 nos irroga a la inevitable declaración de inadmisibilidad contemplada en el art. 340 CPP ... Son cuatro categorías de sujetos procesales que pueden promover la acción de revisión y no figura como tal el abogado defensor del reo aunque haya este figurado como tal en el juicio sometido a revisión ... La interposición determina una situación jurídica procesal nueva y autónoma, diferente a la relación procesal nacida a raíz del ejercicio de la acción penal por el Ministerio Público y que se extingue con el pronunciamiento de la sentencia y con el paso de la misma a la condición de autoridad de cosa juzgada. (Sentencia No. 44, 2004).

El abogado privado no es sujeto legitimado para interponer la acción de revisión. El principio doctrinal enseña "que la revisión es una acción autónoma independiente del juicio que se pretende revisar, cuya secuela llegó a su fin con la sentencia firme pasada con autoridad de cosa juzgada" y es en esta nueva acción, autónoma, en donde apenas se va a nombrar al abogado que defenderá al condenado que somete a revisión la sentencia que lo condenó ... La interposición de la revisión la suscribió el abogado acusador, quien no está legitimado para interponer la revisión, lo que enerva la consecuente declaratoria de inadmisibilidad ... (Sentencia No. 24, 2005).

Al defensor privado no le está permitido el derecho de la impugnabilidad subjetiva por no encontrarse legitimado. 
La petente no señala los datos históricos de la sentencia que se trata de revisar, fluye de la documentación acompañada, que es la dictada por un juez de primera instancia, pero esta decisión junto con el veredicto de no culpabilidad es favorable a la acusada, lo que veda entrar a su conocimiento por imperativo del principio de impugnabilidad, que procede únicamente contra la sentencia condenatoria y no absolutoria ... La accionante es la ofendida y no se encuentra legitimada para promover la revisión, encontrándose en contraposición al principio de impugnabilidad subjetiva. (Sentencia No. 14, 2004).

Pueden también ejercer la acción de revisión el cónyuge, el compañero en unión de hecho estable, los parientes dentro del segundo grado de consanguinidad, si el condenado ha fallecido. Esta situación implica que si el condenado falleció sin haber promovido acción de revisión la ley les faculta formularla, teniendo como objeto la reivindicación del condenado después de su muerte.

El procedimiento de revisión es una acción limitada por sus motivos, se basa en el estudio y análisis de las causales que en forma específica y que con criterio riguroso de "numerus clausus" señala el art. 337 $\mathrm{CPP}$, que a su vez deben ser claramente expresadas en la interposición de la acción de revisión, por eso no basta solo enunciarlas, sino que es necesario razonar el por qué concurre esa causal en el accionar. Cuando la acción de revisión esté sostenida en una nueva valoración del material probatorio acumulado en el proceso con anterioridad a la condena firme, debe ser declarado inadmisible.

\section{Requisitos formales bajo pena de inadmisibilidad}

La revisión será interpuesta, por escrito, ante el tribunal competente. Contendrá, bajo pena de inadmisibilidad, la concreta referencia de los motivos en que se basa y las disposiciones legales aplicables. Se acompañará, la prueba documental que se invoca, indicando, si corresponde el lugar o archivo donde ella está. Deberá ofrecerse los elementos de prueba que acreditan la causal de revisión que se invoca. En el escrito inicial, deberá designarse a un abogado defensor. Si no lo hace, el tribunal lo prevendrá, sin perjuicio de la designación de un defensor público o de oficio, según corresponda, cuando sea necesario. 
Como parte de las exigencias para que la solicitud tenga entrada, debe exponer claramente cada uno de los motivos en los que se sustenta tal petición, indicándose a la vez en cada casolos preceptos legales que se estiman como inobservados o erróneamente aplicados, es decir, la norma vulnerada y la conmina la nulidad de su omisión o de su realización como defectuosa ... Además cada aparte debe contener la exposición concreta de los fundamentos de hecho y de derecho del reproche, pues en caso contrario se debe rechazar lo pretendido, esto significa que la inadmisibilidad de un procedimiento de revisión puede obedecer a tres hipótesis a) cumplimiento de formalidades, b) presentación fuera de las hipótesis que lo autorizan y, c) cuando resulta manifiestamente infundada. De manera genérica e indiscriminada el accionante acusa una serie de defectos, en un solo aparte sin respetar la debida separación de motivos, lejos de acreditar jurídicamente los defectos o yerros que en ella se acusan, lo que pretende en realidad es un nuevo y parcial análisis de los diferentes elementos de juicio que fueron discutidos por el a - quo. (Sentencia No. 15, 2004).

La finalidad de la acción es dejar sin efecto un fallo firme, y es necesario que al interponerse se cumpla un mínimo de formalidades prescritas como señalar "la concreta referencia de los motivos en que se base y las disposiciones legales aplicables”... Es indispensable que los motivos sean expuestos separadamente en forma definida al igual que sus fundamentos, o si se formulan conjuntamente al menos que de su redacción se puedan desglosar las razones en que se fundan cada causal, lo que "en concreto" no ha hecho el petente; porque no ha separado los motivos; ni ha señalado cual es la sentencia impugnada; de dónde proviene y en qué fecha se dictó; no indicó si sobre esa resolución pende recurso alguno o si por el contrario se encuentra firme; por esa razón no es posible que la Sala cumpla la función de suplir las omisiones del solicitante y por ello debe declararse inadmisible. (Sentencia No. 20, 2004).

El accionante no cumplió con identificar la sentencia condenatoria pedida de revisión. Ha sido criterio de la Sala que la revisión se declarara inadmisible, cuando la petente manifieste su inconformidad con el fallo condenatorio a través de una 
crítica subjetiva, genérica, y cuando omita señalar los motivos en concreto de lo que se estima se cometió algún error judicial que deba subsanarse en esta vía; por lo que al comprobar que no ha cumplido con los requisitos legales debe declararse la inadmisibilidad de la acción intentada ... (Sentencia No. 2, 2005).

Es necesario que al interponerse se cumpla un mínimo de formalidades prescritas ... como identificar plenamente la sentencia de la que se pide revisión, debe limitarse a indicar el tribunal de juicio; señalar las disposiciones violadas y en quéforma se viola, señalar las disposiciones legales aplicables, acompañar la prueba documental que se invoca, demostrar si sobre esa resolución pende recurso o si por el contrario se encuentra firme ... (Sentencia No. 59, 2005).

Debe existir correlación entre el motivo de la revisión, las normas violadas y la norma aplicable ... No se subsanan errores ... Los recurrentes hacen uso de una modalidad propia del recurso de apelación a tal punto que cuando interponen la acción lo hacen pretendiendo hacer valer causales propias del recurso de casación ... Hacen una exposición indiferenciada de los supuestos vicios, no mencionan los motivos en que basan, ni mucho menos que hayan identificado en su narrativa desordenada la íntima correlación que debe existir entre el motivo de la revisión, las normas violadas y la norma aplicable. No obstante se le previno a los accionantes subsanar los errores y no lograron subsanarlos. (Sentencia No.30, 2005)

Por haberse inobservado en su interposición ciertas formalidades y por que el accionante hace una exposición indiferenciada de los pretendidos vicios sin ofrecer una comprobación autónoma de su existencia, que, del libelo se colige, no haber cumplido con la formalidad primordial de identificar con precisión la sentencia condenatoria pedida de revisión, de omitir el requisito de separación de los motivos y sus fundamentos, no hacer el señalamiento de los nuevos hechos o nuevos elementos de pruebas que fundamenten las causales e ignorando hacer el señalamiento de las disposiciones legales aplicables al amparo de la supra citada disposición, y de habérsele prevenido. (Sentencia No. 34, 2005). 


\section{Motivos o causales de revisión}

1. Cuando los hechos tenidos como fundamento de la condena resulten inconciliables o excluyentes con los establecidos por otra sentencia penal firme

Alude directamente al dictado de un fallo posterior y pasado en autoridad de cosa juzgada y se refieren a la neutralización de la prueba de cargo a partir de la nueva sentencia que la desmerece definitivamente. Las diferencias deben referirse a circunstancias de modo, tiempo o lugar, esenciales y penalmente relevantes, que se oponen o contradicen entre sí.

Esa inconciliabilidad se presenta cuando las conclusiones de hecho establecidas en la sentencia impugnada contrastan ostensiblemente con ese mismo tipo de conclusiones fijadas en otra sentencia penal firme, absolutoria o condenatoria, sin importar el tribunal que la haya dictado y de la circunstancia de que sea anterior o posterior al fallo en revisión; tiene su fundamento en la afectación que puede ocurrir al principio de contradicción en sus contrastes de detalle respecto a la determinación circunstanciada del hecho que se estimó acreditado en cada una de ellas.

Existe también inconciabilidad si alguno de los hechos en que se basa la sentencia recurrida es contradicho por alguno de los fijados en otra sentencia penal firme, y esa inconciabilidad debe existir entre dos sentencias penales firmes, no entre una penal y otra civil, por ejemplo existe inconciliabilidad, sí, la sentencia recurrida se funda en que el condenado cometió el delito en determinado lugar y la otra sentencia establece que en ese mismo tiempo el condenado se encontraba en otro lugar; o si una sentencia se funda en que el autor de un hecho es una persona y los fundamentos de otra sentencia establecen que el autor de ese mismo hecho es un tercero; si la sentencia impugnada condena por homicidio de una persona al que una sentencia ulterior le considera víctima de otro delito o si una de las sentencias establece que el delito solo pudo cometerse por una sola persona y la otra condena a varios. 
2. Cuando la sentencia condenatoria se haya fundado en prueba falsa $o$ en veredicto ostensiblemente injusto a la vista de las pruebas practicadas

Lleva como fin neutralizar la prueba de cargo en que se fundó la sentencia impugnada agregando el otro supuesto que es la falta de correlación entre el veredicto considerado injusto frente a las pruebas practicadas.

Esta causal no se supedita a una declaratoria jurisdiccional posterior de falsedad como otras legislaciones lo exigen, lo que significa que no es necesario el hecho de que con posterioridad a dictarse el fallo impugnado, deba haber recaído otra sentencia mediante en la cual se demuestre con certeza la falsedad de la prueba que sirvió de apoyo a la condena decretada. El Tribunal de revisión no establece de manera alguna la falsedad de la prueba en que se sustenta la sentencia, sino que valorándola conjuntamente con la ofrecida, opta por otorgarle mayor credibilidad a una u otra.

También subsiste la posibilidad de atacar la prueba del fallo de instancia, mediante la causal $5^{\mathrm{a}}$. Cuando sobrevengan o se descubran nuevos hechos o elementos de prueba, pues en esta hipótesis, es posible contradecir la prueba ya valorada pero de una forma mediata, por razón de la indicación de nuevos hechos o el ofrecimiento de elementos de prueba que resulten novedosos en el proceso. Motivo común o usual en los escritos de revisión.

De lo alegado y aportado por el accionante con base a las causales $2^{\mathrm{a}}$ y $5^{\mathrm{a}}$ se denota que son las mismas declaraciones testificales analizadas en el proceso con las que pretende probar que su defendido es inocente ... lo que no constituyen un hecho o punto nuevo que pueda cambiar la apreciación de los hechos, pues se limita a atacar un fallo de conciencia que no es sentencia, pues de las pruebas analizadas en juicio se infiere que fue el condenado el autor del delito ... Los argumentos de la defensa se aferran a que no hubo testigos presenciales de los hechos, pero rola el dictamen médico legal, la valoración psicológica de la víctima, y la propia declaración de la menor. (Sentencia No. 42, 2004).

En relación con la causal $2^{\mathrm{a}}$ alegada por el recurrente en correlación con la prueba falsa consistente en datos errados en la identificación de su defendido quien lo ha llamado con tres nombres ... La accionante debió señalar de forma clara las causales que invocó ya que la causal $2^{\mathrm{a}}$ se refiere a la prueba falsa 
y fue un Tribunal de Jurado el que encontró culpable al acusado, y no es posible conocer cuál fue la prueba en la que se fundó el veredicto, además que señaló como prueba falsa la identificación del acusado, cuando es permitido corregir cualquier error en la identidad del acusado, por lo que no constituye causa de anulabilidad y falsedad ... En relación con la causal $5^{\text {a }}$ los nuevos hechos son los testigos que la accionante presento en la audiencia revisoría, pero no cambia en nada la situación de hecho. El error de identidad fue corregido y la prueba testifical aportada no tiene mérito para revertir el proceso ... El veredicto pronunciado no ha sido ostensiblemente injusto por lo que debe considerase esta causal como no probada y así debe declararse. (Sentencia No. 48, 2004).

En relación con la causal $2^{\mathrm{a}}$ alegada, está procede cuando la sentencia condenatoria se ha fundado en prueba falsa o en veredicto ostensiblemente injusto a la vista de las pruebas practicadas. El recurrente alega que en el juicio oral y público no compareció ningún testigo que incriminara de forma directa a su defendido y que sólo existía la versión de la propia víctima que se retractó, después que el acusado había cometido el hecho, siendo los testimonios de la menor y de los padres determinantes para que el Tribunal de Jurado emitiera un veredicto de culpabilidad por lo que no resulta lógico alegar veredicto ostensiblemente injusto cuando concurrieron los elementos típicos y antijurídicos del delito de violación ... El condenado ataca hechos que ya fueron valorados y juzgados durante el proceso y los quiere reproducir como si se tratara de errores "in judicando" lo cual no es permitido ... La supuesta contradicción entre los dos dictámenes médicos realizados no tiene fundamento para sustentar la primera causa alegada. No se observa que el veredicto dictaminado por el Tribunal de jurado haya sido ostensiblemente injusto por lo que debe considerase esta causal como no probada e inexistente y así debe declararse. (Sentencia No. 54, 2004).

El petente motiva su revisión bajo la causal $2^{\mathrm{a}}$ y de los hechos planteados en la acusación que dio origen al juicio en donde fue condenado el acusado como autor directo del delito de violación y lesiones. El accionante pretendió demostrar que existía contradicciones entre el dictamen médico legal, testifical 
de la oficial de la policía, y la testimonial de la víctima, y se llega a dos conclusiones: a) No existen pruebas de que la violación efectivamente haya ocurrido, b) En cuanto a las lesiones, pese a que existe dictamen médico legal, en cuanto a la participación del procesado, de la misma declaración de la víctima se desprende que el acusado no fue el autor, antes bien, debería hablarse de complicidad, en caso que se demostrara el nexo subjetivo... De lo antes expuesto se colige como lógico corolario la procedencia de la presente acción de revisión bajo el alero de la causal $2^{\mathrm{a}}$ pues las otras invocadas por el petente, resultan impertinentes a la luz de los argumentos planteados y analizados. La testifical de la víctima se disuelve ipso facto la participación del encartado como autor en los delitos investigados, y por lo que hace al delito de lesiones, en las que existen otros elementos probatorios que hacen meritorio una nueva valoración en juicio, por haber devenido en el caso citado un fallo ostensiblemente injusto por las consideraciones antes expuestas. Ante la hipótesis legal contenida en la causal $2^{\mathrm{a}}$, resulta procedente y se debe procederse al reenvío de la presente causa penal al juzgado subrogante a fin de que conozca del presente juicio por lo que hace a la causa seguida en contra del acusado, como cómplice únicamente del delito de lesiones. (Sentencia No. 58, 2004).

3. Si la sentencia condenatoria ha sido pronunciada a consecuencia de prevaricato, cohecho, violencia, maquinación fraudulenta o cualquier otro delito cuya existencia se haya declarado en fallo posterior firme salvo que se trate de alguno de los casos previstos en el inciso siguiente

$\mathrm{Al}$ igual como ocurre en el primer motivo, también alude a los fallos posteriores e irrevocables. La acción de revisión es como consecuencia de ciertos delitos, requiriéndose que la comisión de los mismos haya sido declarada previamente por sentencia penal firme.

Este motivo está referido al vicio de la voluntad jurisdiccional que no atiende el resultado de la sentencia condenatoria, por haberse dictado ese fallo condenatorio como consecuencia directa de un delito de prevaricato, cohecho, etc. Es requisito sine qua non que, la condena haya obedecido al prevaricato o al cohecho, dichos delitos deben haber tenido directa incidencia en la sentencia condenatoria, lo cual no opera cuando el acusado es declarado no culpable no siendo así cuando el cohecho es ejercido para obtener la condena. 
La violencia o maquinación fraudulenta se relaciona también con otros delitos, como la coacción, la extorsión o la estafa procesal, realizada por el juez, o el imputado causando de este modo el error judicial, y es este el que deberá ser analizado por el tribunal de revisión para establecer la existencia o relación de causalidad entre el cohecho, prevaricato, u otros delitos antes mencionados y el pronunciamiento de la sentencia condenatoria impugnada. Al usar la ley el término de "maquinación fraudulenta" se refiere a los delitos cometidos mediante fraude.

4. Cuando se demuestre que la sentencia es consecuencia directa de una grave infracción a sus deberes cometida por un juez o jurado, aunque sea imposible proceder por una circunstancia sobreviniente

Cuando el juez o jurado infringe sus deberes y es la causa determinante para la condena, cuando el juez comete prevaricato y actúan con culpa en la resolución de la causa que le fue sometida, produciéndose en consecuencia una sentencia injusta en los hechos o en lo atinente al fundamento jurídico. Existiendo otro supuesto y, es cuando la sentencia condenatoria obedeció a la comisión de un delito cuya víctima fue el juez, tal es el caso de los delitos de amenazas, extorsión, o incidió sobre la prueba o el trámite de la causa por ejemplo, cuando el juez produce una alteración fraudulenta del estado de las cosas o del significado de la prueba relacionados con el delito que determinó la condena.

Para estos supuestos es imposible proceder por circunstancias sobrevivientes, aunque es una excepción a la regla, igual ocurre cuando el juez miembro del tribunal de jurado o acusado hubiese fallecido, el despido del juez, prescripción del delito, etc. La infracción del juez deberá ser directamente demostrada en la acción de revisión, ofreciendo la prueba pertinente para ello.

5. Cuando después de la condena sobrevengan o se descubran nuevos hechos o nuevos elementos de prueba que, solos o unidos a los ya examinados en el proceso, evidencien que el hecho o una circunstancia que agravó la pena no existió, que el condenado no lo cometió o que el hecho cometido no es punible o encuadra en una norma más favorable

Está referido a nuevos hechos o elementos probatorios que modifiquen el criterio ya establecido en la sentencia impugnada y que deben evidenciar: 
a) que el hecho o una circunstancia que agravó la pena acreditada en la sentencia en realidad no existió; b) que el condenado no lo cometió; c) que el hecho cometido no es punible o encuadra en una norma más favorable.

Un nuevo examen, una nueva revaloración de la prueba ya incorporada y valorada oportunamente en el juicio, no es sujeto de nueva valoración, pues solo puede confrontarla o relacionarlas con nuevos elementos probatorios para apreciar si el resultado del análisis modifica el sentido de la decisión. Por esa razón, es necesaria la aparición de evidencias distintas a las ya incorporadas al proceso, de modo que por sí solas o unidas a las ya examinadas modifiquen sustancialmente la situación procesal del condenado, motivo por el cual es improcedente la acción de revisión cuando está orientada a examinar cuestiones que ya fueron valoradas en la sentencia impugnada.

Para que pueda acordarse la nulidad de la sentencia impugnada bajo esta premisa, se requiere: 1. La presencia de una sentencia firme. 2. Que su contenido sea condenatorio. 3. Que con posterioridad a dicha sentencia aparezcan nuevos hechos o nuevos elementos de prueba. 4. Que estos nuevos hechos o nuevos elementos de prueba sean de tal naturaleza que evidencien la inocencia del condenado.

No es suficiente que el hecho o la prueba sean nuevos, o que sobrevengan o aparezcan después de dictada la sentencia sino que también a pesar de existir con anterioridad no fueron tomados en cuenta al dictarse la sentencia por desconocerlos o por que el accionante los descubrió posteriormente. Esa prueba debe justificar el error padecido por el juzgador de manera exacta, con certeza, indubitada y patentice sin lugar a dudas la necesidad de rectificar la condena en otra más beneficiosa para la persona condenada.

Cuando la ley se refiere a que el "hecho encuadre en una norma más favorable", está limitado a la ley sustantiva y no a la procesal, porque sólo respecto de la primera es dable hablar de encuadrar o subsumir un hecho en la norma. Es por esa razón que el accionante debe ofrecer y acreditar nuevos hechos o nuevas pruebas que justifiquen aplicar otra norma que permita encuadrar el hecho en una norma penal más favorable al condenado. 
El gestionante invoca la causal $5^{\mathrm{a}}$ del art. 337 CPP que está supeditada al descubrimiento de nuevos hechos o nuevos elementos de prueba que demuestren en grado de "evidencia" el error cometido por el juzgador y que consecuentemente puedan servir para fundamentar una decisión revocatoria en revisión, de modo que la admisibilidad de la pretensión revisora debe descartarse cuando aparece fundada en elementos de mera posibilidad o probabilidad acerca de los mencionados extremos, pues se desprende, que el accionante propone dos testificales con quienes pretende, demostrar con sus dichos que es imposible haber cometido el delito de violación acusado, hecho que ha quedado establecido en el proceso y confirmado en el juicio oral y público, pues además dicha prueba propuesta de, ser admisible, no evidenciaría una inculpabilidad y resultara huérfana en su fin pretendido que trata de revertir aquel fallo de culpabilidad emitido y trata de revertir la valoración de las pruebas ya valoradas en juicio y cuya falta cometida pudo ser objeto de valoración a través de los medios de impugnación y no por esta vía revisora. La presente acción no cumple con los requisitos indispensables de fundadibilidad objetiva ... (Sentencia No.47, 2005).

La acción de revisión, requiere una interpretación rigurosa en las causas que lo viabilizan, a fin de evitar que se convierta en un nuevo grado jurisdiccional en el que, al arbitrio de los litigantes y con menoscabo de la cosa juzgada, se intente volver a discutir casos ya debatidos y definitivamente resueltos. (Sentencia No. 35, 2003).

En relación con la causal $5^{\text {a }}$ del art. 337 del CPP, alega el recurrente que el delito por el que fue condenado no fue cometido por él, sino por otra persona ... A pesar de la importancia de la cosa juzgada no puede ser absoluta porque puede entrar en colisión con los fines de un estado social de derecho, que tiene como objetivo velar por que prevalezca la justicia ... Para enfrentar estas situaciones la mayoría de las legislaciones prevén excepcionalmente, dejar sin valor una sentencia ejecutoriada, cuando hechos o circunstancias posteriores a la sentencia firme permiten concluir que existe una injusticia.- En relación con la posibilidad de "nuevos hechos" que 
posibilitan hacer una nueva valoración para considerar que el condenado no cometió el hecho que se le imputó. El condenado alegó que un Tribunal de Jurado lo encontró culpable por el delito de violación, y que la víctima manifestó que la persona acusada no era la persona que la había violado y que había sido otra persona, y que ante esta nueva situación interpuso revisión .: En relación con este "nuevo hecho" que desvanece totalmente las pruebas en que se sustentaba la culpabilidad del condenado y en virtud del Principio "In Dubio Pro Sententiae". Por lo que, en base al testimonio donde aclaran que el acusado no fue la persona que la violó y ante este nuevo hecho que desvanece la responsabilidad penal del condenado resultarían innecesarios el reenvío de la causa y un nuevo juicio. En base a los principios constitucionales supra debe concluirse que en base a este nuevo hecho, el reo no cometió el ilícito por el que fue acusado y condenado, por lo que la Sala debe pronunciase directamente respecto a la sentencia que en derecho corresponde. (Sentencia No. 54, 2004).

Como único motivo de la acción de revisión, el sentenciado reclama, al amparo del numeral $5^{\mathrm{a}}$ del art. 337 del CPP, la existencia de "nuevos hechos o nuevos elementos de prueba"; en virtud de Certificación de Reposición de Partida de Nacimiento que demuestra su minoría de edad y en consecuencia la incompetencia del juez de distrito penal para sentenciarlo como la del tribunal para confirmar dicha sentencia. "Nuevos hechos o nuevos elementos de prueba" son aquellos que con posterioridad a la sentencia condenatoria son revelados, sin importar que el condenado tuviere conocimiento sobre ellos durante la sustanciación de la causa, por lo tanto deberán ser considerados "nuevos" -los hechos o elementos probatorios- cuando no hayan sido descubiertos por la investigación del Ministerio Público o la Policía Nacional ni invocados o producidos por las partes procesales, ante el juez o tribunal competente, es decir que no hayan sido tenidos en cuenta por la autoridad que condena. No podrá considerarse como "nuevo" el hecho o elemento probatorio que ha concurrido al proceso y no fue apreciado por el juez o tribunal de apelaciones ... Se observa que la Certificación de Reposición de Partida de Nacimiento, no constituye "nuevo" 
elemento probatorio, puesto que el Tribunal de Apelaciones, admitió dicha certificación como prueba aunque sin darle valor probatorio, aduciendo en la sentencia, que la certificación referida no puede tenerse como prueba lícita que desvirtúe lo establecido por el dictamen médico legal ... La Certificación en cuestión no puede considerarse como nuevo elemento de prueba y la acción no puede fundarse en la falta de valoración de prueba ofrecida, lo cual es propio del recurso de casación. (Sentencia No. 35, 2004).

Por otra parte, sirva al accionante, que la revisión al amparo de la causal prevista en el numeral 5 del art. 337 CPP por "hechos nuevos" o "nuevos elementos de prueba", está destinada a confrontarlos con los elementos probatorios tenidos en cuenta en la sentencia, siempre que sea viable hacerlo posteriormente al fallo, por su desconocimiento o por algún otro motivo de imposibilidad absoluta previa, aquí no está en una etapa procesal para cuestionar la verosimilitud o no de un medio probatorio en sí mismo o con relación a otras pruebas evacuadas durante el juicio tal a como lo pretende el petente, es decir, que en la propuesta del condenado significaría hacer una nueva valoración de la prueba ya rendida y que es propio aquel juzgador que utiliza los principios de la inmediación y la concentración pero no del supremo tribunal, pues las pruebas propuestas en todo caso en nada "evidenciarían" lo contrario a la irreversible culpabilidad ya declarada en juicio. (Sentencia No. 59, 2005).

La inexistencia del hecho, la no participación de la persona condenada o el encuadramiento de su conducta en una norma penal más favorable debe quedar demostrada en grado de evidencia, porque de lo contrario la acción de revisión debe declararse inadmisible ya que es motivada por elementos de mera posibilidad o probabilidad y que solo generan dudas pero no certeza alguna para dar lugar a la revisión.

6. Cuando deba aplicarse retroactivamente una ley posterior más favorable, o cuando la ley que sirvió de base a la condenatoria haya sido declarada inconstitucional

Esta causal autoriza recurrir de revisión para aplicar en forma retroactiva una ley más favorable, por la aprobación de una nueva legislación, que 
haya señalado que el hecho ya no es punible, o bien cuando la norma que sirvió de base para la condenatoria ha sido declarada inconstitucional.

No debe aplicarse el procedimiento que otorga el Código Procesal Penal para accionar de revisión ante la Sala Penal como consecuencia de sobrevenir una legislación más favorable, promulgada con posterioridad a la condena, pues estaríamos ante una revisión de mero derecho y no necesita ser recurrida ante las Salas Penales de los Tribunales competentes. Debería de aplicar la retroactividad de la ley más favorable al condenado el juez o tribunal que tenga a cargo la causa. El articulo 404 del Código Procesal Penal establece que "El Ministerio Público, el acusador particular, el querellante, el condenado o su defensor podrán plantear ante el competente Juez de Ejecución de la pena incidentes relativos a la ejecución, sustitución, modificación o extinción de la pena o de las medidas de seguridad".

7. Cuando se produzca un cambio jurisprudencial que favorezca al condenado, en las decisiones de la Corte Suprema de Justicia o sus salas

El cambio jurisprudencial es causa de revisión, aunque no sea hecho nuevo, siempre y cuando favorezca a la persona condenada. La jurisprudencia en nuestro ordenamiento jurídico no constituye fuente formal del derecho objetivo pero obliga a juez y magistrado a resolver de acuerdo con los fallos judiciales precedentes y solo podrán modificar el precedente explicando detalladamente las razones que motiven el cambio.

\section{Formalidades de la acción de revisión}

La acción de revisión carece de plazo para ejercerla, lo que permite a los sujetos procesales hacer uso de ella en el momento que surjan los elementos para su procedencia.

El Código Procesal Penal establece exigencias formales para la interposición de la acción que de no cumplir con las mismas será declarada inadmisible. 


\section{Otros requisitos a cumplir}

1. Indicación de cuál de los motivos previstos en el art. 337 CPP se invoca, 2. Razones que prestan apoyo a tal invocación. 3. Exposición diferenciada y su importancia, de los pretendidos vicios. 4. Fundamentación jurídica, para no quebrantar de ese modo la concreta referencia de los motivos en que se basa y las disposiciones legales aplicables que indica el art. 339 CPP. Lo que resulta necesario cuando se pretende el encasillamiento del hecho en una norma penal más favorable o la aplicación de una pena más benigna.

De manera genérica e indiscriminada el accionante acusa una serie de defectos, en un solo aparte-sin respetar la debida separación de motivos ... lo que pretende en realidad es un nuevo y parcial análisis de los diferentes elementos de juicio que fueron discutidos por el a-quo; nuevo análisis que además tiene el propósito de revertir las conclusiones que se hacen constar en el pronunciamiento, sin explicarse las razones de orden jurídico para ello, pues pretende en forma retroactiva la aplicación al caso concreto de una ley posterior sin mencionar siquiera cual es esa ley, e incluso no logra hacer una identificación de la sentencia dictada en contra del accionante y que ahora se pretende revisar. Esta forma de presentar la solicitud resulta absolutamente inadmisible. (Sentencia No. 15, 2004).

El recurso de revisión que presenta el accionante no puede ser atendido por no ajustarse a lo prescrito en el art. 339 del CPP; 1. Al exponer mezcla aspectos de diversa naturaleza, como por ejemplo: apreciaciones subjetivas sobre el actuar del fiscal en el proceso, la alegación de falta de credibilidad de las pruebas testimoniales presentadas en el juicio, hace críticas de la manera en que sus testigos ofrecidos no fueron admitidos; un sin número de reproches que hace de las pruebas y que son propios de un recurso de apelación; 2. Tratándose de una acción que tiene por finalidad dejar sin efecto un fallo firme, es necesario que al interponerse se cumpla un mínimo de formalidades, como señalar "la concreta referencia de los motivos en que se base y las disposiciones legales aplicables". Es indispensable, que los motivos sean expuestos separadamente en forma definida al igual que sus fundamentos, o si se formulan conjuntamente, al menos 
de su redacción se puedan desglosar las razones en que se funda cada causal, lo que "en concreto" no ha hecho el petente ... no es posible que la Sala cumpla la función de suplir las omisiones en que ha caído el solicitante y por ello debe declararse inadmisible. (Sentencia No. 20, 2004).

Los defectos formales en la puntualización de esos extremos, bien podrían ser objeto de prevención, cuando la acción haya sido presentada fuera de la hipótesis que la autorizan o resultara manifiestamente infundada, el Tribunal de oficio declarará su inadmisibilidad, sin perjuicio de la prevención correspondiente.

La revisión puede desestimarse de plano cuando es promovida por quien carece de titularidad o el escrito no reúne los requisitos exigidos.

\section{Inadmisibilidad de la acción de revisión}

Se declara la inadmisibilidad de la acción de revisión cuándo: 1. El recurrente manifieste su inconformidad con el fallo condenatorio a través de una crítica subjetiva y genérica en donde se mezclan aspectos de diversa naturaleza. 2. Cuando omite señalar los motivos concretos de lo que se estima se cometió algún error judicial que debe ser subsanado en esta vía. 3. Si resultara manifiestamente infundada, como ocurre por ejemplo cuando el accionante fundamenta la revisión en la aprobación de una nueva ley, pero resulta que la pena impuesta al delito por el cual ha sido condenado es la mínima que prevé la nueva ley; en este caso el sentenciado no obtendría ninguna ventaja si se declarara con lugar la revisión planteada, ya que la pena impuesta permanecería incólume. 4. Por lo que hace a los motivos reclamados en casación en cuanto a la violación del debido proceso y que fueron resueltos sin lugar, y que son argumentos contenidos en la acción de revisión, en este caso no es posible analizarlos de nuevo.

Del estudio del escrito de la acción de revisión intentada se nota que ha incumplido en la formalidad que exige esta clase de procedimiento, pues se limita a señalar que interpone la acción sobre la base de lo preceptuado en el art. 337 CPP incisos 2 y 4, sin embargo al desarrollar sus argumentos se dirige al motivo $1^{\circ}$ de revisión y luego al motivo 2 , sin dirigirse correctamente y sin 
duda alguna a la causal que corresponde, pues no se sabe si el motivo número 1 es la causal $2^{\mathrm{a}}$. y el 2 la causal 4 o viceversa; siendo este desarrollo de petición que de entrada es suficiente para declararla infundada, cabe señalar, que su exposición no cuenta con el asidero legal propio, y manifiesta que el juez que condujo el proceso cometió infracciones en su proceder, pero estos reclamos son propios examinar a través de los medios de impugnación o como actividad procesal defectuosa, que exige la oportuna protesta para hacer valer los derechos de las partes cuando se trata de reclamos por violaciones en la aplicación del derecho procesal, pero nunca es posible hacerlo a través de la vía de la acción de revisión ... El petente no ofrece las pruebas requeridas para acreditar las causales de revisión ... (Sentencia No. 91, 2006).

\section{La prueba en la acción de revisión}

El art. 339 CPP, obliga al que promueve la acción revisoria a ofrecer los elementos probatorios que sirvan para fundamentar su alegato, y el art. 340 del mismo cuerpo de leyes permite en la audiencia oral la recepción de material probatorio útil para resolver el procedimiento de revisión; razón por la cual se hace indispensable que quien ofrece la prueba señale la relevancia de la misma relacionándolo con la causal en que basa el reclamo, debiendo observar ciertas reglas para que las pruebas que ofrecen las partes sean admitidas, así cuando el ofrecimiento de una prueba documental, debe acompañar el documento que invoca, esto ocurre cuando está al alcance del solicitante, pues de lo contrario la ley solo le obliga a señalar el lugar donde se encuentra. Cuando se trate de testimonios, deberá indicarse su nombre, datos personales y domicilio, así como los hechos o circunstancias que se pretenden demostrar con ellos, cumpliendo así con lo preceptuado en la disposición precitada que señala "para que comparezcan con los medios de pruebas que funden la acción o se opongan a ella”.

\section{Efecto suspensivo de la ejecución de la sentencia como medida excepcional}

La suspensión de la ejecución de la sentencia y la posibilidad de disponer la libertad provisional de la persona condenada durante el procedimiento de revisión, constituye una facultad realmente extraordinaria, siendo una medida de carácter excepcional que procede cuando pueda preveer 
la viabilidad de dejar sin efecto el fallo condenatorio en virtud de la solicitud de revisión. Su ejercicio potestativo exige necesariamente una contundente fundamentación que así lo justifique, como sucede, cuando el error judicial resulta notorio y que de mantenerse su ejecutividad podría acarrear serias consecuencias en los derechos de la persona condenada, en particular en lo concerniente a su libertad.

No existe antecedente en que la Sala Penal de la Corte Suprema de Justicia decretase la libertad en audiencia oral y pública, pero si ha ordenado la libertad una vez resuelto el fondo de la acción revisoría, mediante sentencia en la que da lugar a la acción de revisión.

\section{Sentencia, reparación y efectos}

El Tribunal deberá pronunciarse sobre la acción de revisión intentada, en el plazo de diez días después de efectuada la audiencia y podrá 1. Anular la sentencia, remitiendo a nuevo juicio cuando el caso lo requiera 2. Pronunciando directamente la sentencia definitiva. Así lo establecen los artículos 342 y 343 del Código Procesal Penal.

Artículo 342. Audiencia. Admitida la revisión, la Sala Penal del Tribunal de Apelación o de la Corte Suprema de Justicia, según corresponda, dará audiencia dentro de los diez días siguientes al Ministerio Público y a las partes que hayan intervenido en el proceso principal para que comparezcan con los medios de prueba que funden la acción o se opongan a ella. La diligencia se celebrará con la participación de los intervinientes que se presenten, quienes expondrán oralmente sus pretensiones. Es aplicable en lo que corresponda las disposiciones sobre audiencia oral en el Juicio por Delitos.

Artículo 343. Sentencia. Dentro de los diez días siguientes a la celebración de la audiencia, el tribunal rechazará la revisión o anulará la sentencia. Si la anula, remitirá a nuevo Juicio cuando sea procedente o pronunciará directamente la sentencia que corresponda en derecho. En la revisión, independientemente de las razones que la hicieron admisible, no se absolverá, ni variará la calificación jurídica, ni la pena, como consecuencia exclusiva 
de una nueva apreciación de los mismos hechos conocidos en el proceso anterior o de una nueva valoración de la prueba existente en el primer Juicio.

Sustanciada la pretensión revisora, la sentencia del tribunal puede: 1 . Declarar la inadmisibilidad de la acción. 2. Rechazar la pretensión en cuanto al fondo por no haberse acreditado suficientemente los hechos alegados como fundamento de aquélla. 3. Anular la sentencia impugnada y pronunciar directamente la sentencia definitiva. 4. Anular la sentencia sujeta a revisión y remitir a nuevo juicio cuando el caso lo requiera.

Sin reenvío. Esta alternativa se configura cuando, frente a la certeza de la prueba producida, resulta innecesario un nuevo debate sobre el mérito de la causa, lo que particularmente ocurre, si de aquélla surge, con evidencia, que el hecho no existió o no fue cometido por la persona condenada.

No es necesario el reenvío si se trata de la aplicación de la ley penal más benigna, en cuyo supuesto el tribunal debe, directamente, dejar sin efecto la condena o disminuir la pena impuesta en ella. Asimismo el tribunal podrá ordenar la libertad, la restitución de la multa; cesación de la inhabilitación y de las penas accesorias, de las medidas de seguridad; la devolución de los efectos del comiso; fijar nueva pena o practicar nuevo computo, si corresponde.

\section{Juicio de reenvío}

El juicio de reenvío debe verificarse como consecuencia de la anulación de la sentencia; y esta se halla supeditada a la circunstancia de que, a criterio del tribunal, se imponga la necesidad de un nuevo debate en el punto o puntos que constituyen materia de la revisión, lo cual es algo novedoso. Este nuevo juicio habrá de realizarse para llegar a una nueva sentencia que reemplace a la anulada, en el cual no pueden intervenir ninguno de los jueces o jurados que conocieron del anterior.

El tribunal de reenvío debe someterse a una limitación con relación al imputado: la nueva sentencia no podrá ser más gravosa para la persona condenada que la sentencia anulada en cumplimiento del principio 
que prohíbe la reformatio in peius art. 344 CPP segundo párrafo. El condenado tiene derecho, en tal caso, a mantener por lo menos la misma situación procesal y sustantiva lograda en el juicio anterior.

\section{Efectos de desestimación de la acción}

Cuando se trata de demostrar la absolución de la persona injustamente condenada, prescribe el art. 347 del CPP "El rechazo de una solicitud de revisión y la sentencia confirmatoria de la anterior no perjudicarán la facultad de ejercer una nueva acción, siempre y cuando se funde en razones diversas." Sólo requiere, por lo demás, el aporte de nuevos elementos de juicio y es aplicable aunque el rechazo haya obedecido a razones de inadmisibilidad.

\section{Publicación de la sentencia}

"A solicitud del interesado, el tribunal dispondrá de la publicación de una síntesis de la sentencia absolutoria en un medio de prensa escrito, sin perjuicio de la publicación que por su cuenta realice el acusado."Art. 346 CPP. Puede tratarse de la dictada directamente por el tribunal de la revisión o la que se emite en el juicio de reenvío, con tal de que sea absolutoria.

\section{Conclusiones}

1. Existe una errónea implementación de la acción de revisión en la práctica forense por no hacer uso de los recursos ordinarios y extraordinarios, dejando transcurrir los plazos establecidos para los procesos impugnativos con el fin de que la sentencia condenatoria adquiera firmeza y, una vez firme, proceden a recurrir directamente de revisión utilizando técnicas propias de los recursos.

2. Los accionantes confunden: Los motivos de la acción de revisión con causales propias del recurso extraordinario de casación; otras veces pretenden hacer un nuevo juicio al procurar debatir nuevamente las pruebas examinadas y valoradas en primera instancia; además, omiten encasillar sus reclamos en los motivos propios de la acción de revisión, constituyendo este actuar en una declaratoria de inadmisibilidad. 
3. El desconocimiento de la técnica procesal en esta materia hace que los usurarios en sus escritos expongan o fundamenten sus motivaciones solamente sobre circunstancias de hecho, sin señalar las disposiciones violadas o erróneamente aplicadas, los motivos en que fundamentan su acción y la ley que debe aplicarse.

4. La práctica forense en la mayoría de los casos nos arroja que en los escritos de interposición de la acción de revisión los accionantes no fundamentan por separado los motivos cuando invocan más de dos, no los justifican de forma individualizada, por el contrario lo realizan de manera genérica mezclando hechos, normas y motivos de diversa naturaleza, lo que constituye una técnica inadecuada, que conlleva a la declaración de inadmisibilidad $a d$ - porta.

\section{Recomendaciones}

Una vez analizada la figura de la acción de revisión, los aciertos y desaciertos presentados en la práctica forense en la utilización de los motivos de revisión a la luz de las resoluciones ilustradas, considero las recomendaciones siguientes:

1. Las Barras de Abogados, la Escuela Judicial y las Facultades de Ciencias Jurídicas y Sociales deben promover, organizar e impartir capacitaciones dirigidas a profesionales del derecho, operadores del sistema de justicia penal y estudiantes de derecho sobre las técnicas a desarrollar en la interposición y sustanciación de La acción de revisión para obtener resultados positivos al accionar.

2. La enseñanza aprendizaje debe encaminarse a que los facilitadores transmitan a los discentes técnicas que correspondan a la naturaleza, y características propias de la acción de revisión y estas deben ir orientadas a mejorar la práctica forense en función de cumplir y satisfacer los requisitos de fondo y forma que exige la normativa para obtener resultados verdaderos. 


\section{Lista de referencias}

\section{Textos}

Palacios, L. (1998). Los recursos en el proceso penal. Abeledo Perrot S.

\section{Legislación}

Constitución Política de Nicaragua, publicada en La Gaceta, Diario Oficial No. 5 del 9 de enero de 1987.

Ley No. 406, Código Procesal Penal de la República de Nicaragua, publicada en La Gaceta, Diario Oficial No. 243 y 244 del 21 y 24 de diciembre del 2001.

Ley No. 260, Ley Orgánica del Poder Judicial de la República de Nicaragua, publicada en La Gaceta, Diario Oficial No. 137 del 23 de julio de 1998.

\section{Sentencias}

Libro copiador de Sentencias Penales de la Corte Suprema de Justicia. Sala de lo Penal. Año 2003.

Libro copiador de Sentencias Penales de la Corte Suprema de Justicia. Sala de lo Penal. Año 2004.

Libro copiador de Sentencias Penales de la Corte Suprema de Justicia.

Sala de lo Penal. Año 2005.

Libro copiador de Sentencias Penales de la Corte Suprema de Justicia.

Sala de lo Penal. Año 2006. 